\title{
LUCTA VITAL
}

Por Messias da Fonseca, 4. ${ }^{\circ}$ annista de Medicina.

A' luz de duas theorias - lamarckismo e darwinismo a natureza organisada póde ser do seguinte modo concebida:

Em primeiro lugar, tres factores principaes $-a$ variação individual, resultante da acção de causas internas que desconhecemos actualmente; o meio em que vive o ser e o regimen ao qual está ligado (Lei da adaptação de Lamarck), 一tendem constantemente a modificar, seja de um modo insensivel, seja mais ou menos bruscamente (theoria da mutação de De Vries) as iormas animaes e vegetaes.

Em segundo lugar, graças á acção continua da selecção natural formam-se as especies que se deduzem umas das outras pela descendencia genealogica.

Isto posto, com o intuito de assegurar a sua individualidade sempre em perigo e, consequentemente, estabelecer a perennidade relativa da especie, os seres, animaes e vegetaes, luctam continua e desesperadamente, seja uns contra os outros, seja contra as condições do meio physico.

Nessa lucta intregua pela vida, os seres em geral, e particularmente os animaes, se utilisam de tres poderosas armas que Jhes servem para a defesa e para o ataque.

São ellas: a resistencia, o mimetismo e a symbiose.

\section{A RESISTENCIA}

A resistencia se nos apresenta sob tres aspectos: o mechanico, o physico e o chimico. 
São resistencias mecanicas a corpulencia, a forca muscular, a armadura, o ferrão, as garras, as aspas, a tromba, os ientaculos, os dentes. ., etc., que encontramos em quasi todos os animaes.

Salientam-se entre as resistencias physicas as descargas electricas, (v. g. T'orpedo marmorata, Gymnotis electricus), a emissão de luz, (como se nota na medusa e como o observou nas Photostomiae Guernei o principe de Monaco ao pescal-as nas profundezas do oceano).

São dignas de nota entre as resistencias chimicas as emissões de liquilos causticos, (ex.: batrachios e myriapodes); de liquidos toxicos, (ophidios, arachnideos, escorpionideos, hymenopteros, hemipteros e molluscos cephalopodes); de odores mephiticos (como se percebe nas pentatomidas e lepidopteros e, notavelmente, nas Brachinas, que projectam, pulverisado, um liquido fétido, rico de acido butyrico) ; finalmente, a emissão de côres, que se nota nos lepirlopteros e nos batrachios.

\section{O MIMETISMO}

Mimetismo é a propriedade que têm os animaes de tomar a côr do ambiente em que vivem (mimetismo protector ou defensor) cambiando de aspecto e de fórma conforme as necessidades do momento.

Ha tres especies de mimetismo: o mimetismo propriamente dito, o mesoidismo e a homochromia.

O mimetismo propriamente dito se dá não só quanto á côr, mas tambem quanto ao aspecto e á forma que o animal apresenta em relação aos objectos que o cercam.

Quanto á côr temos como exemplos as Vulneratas, que podem imitar todas as côres; ; o famoso Kallima, borboleta da região Indo-malasia que, em actividade, tem o corpo de côres brilhantes e em repouso imita com suas azas uma folha secca, etc.

Quanto ao aspecto, temos o Longicorneus odontocerus que imita o genero Odynerus; o Lophonocerus latreilli, que imita o Coleopterus brasiliensis; certos Pierides e Papillionidas, que fingem as Heliconidas de gosto desagradavel e que os passaros 1ão comem; os lepidopteros Macroglossa Ochs (Titan em são I'aulo. Tantalus no Rio de Janeiro e Stellarum na Inglaterra) 
observados por Gould, todos crepusculares e da especie das Esphyngideas, que imitam os beija-flôres; e ainda algumas serpentes inoffensivas que tomam a côr, as manchas e até os movimentos das cobras venenosas, como se nota com a cobra viperina que imita a vibora.

Tratando-se do mimetismo mesoidismico, temos os animaes que imitam cascas ou galhos, folhas, flôres e até fructos.

Os mais communs imitadores de cascas ou galhos são a Ageronia, lepidoptero notavel por, estando quieto, espalmar as azas; as Ithomidias, imitadoras de galhos seccos; o Cladomorpho phyllino, o Ceroys perfoliatus, que imitam galhos verdes; os louva-Deus (mantidas), o Acridio migrans e a Gastropacha quercifolia, que imitam folhas; as Conognathas, as Vulneratas, as Eacles penelops e tambem as Memphicas, que ímitam flôres; e.finalmente a Membratio fuscata e a Umbonia spinosa (em grupo !, que imitam fructos. São ainda exemplos de mesoidismo a Cicindella nioca, o leão do deserto, o leão da Nubia e o Saurius anguis, que imita os cipós.

Por fim, temos o mimetismo homochromico ou homochromía, que é a modificação voluntaria da côr do animal, podendo ser fixa, quando o animal se adapta á côr do meio, v. g. a Aecedoma cephalote, de côr terrosa, a Lacerta veridea (verde), a Catopsila eubuli (amarella); muitos animaes que vivem sobre a neve e que são sempre brancos; outros, pelagicos, que são absolutamente transparentes; ou podendo ser variavel e, neste caso, é liquida ou chromatica.

Como exemplo de homochromia variavel liquida temos o Octhopus vulgaris e como exemplo de homochromia variavel chromatica, temos o Chamelio vulgaris.

Os phenomenos da homochromia se processando mais ou menos rapidamente quando o animal troca de meio, v. g. o cameleão, são devidos a reflexos nervosos, que determinam a contração ou a dilatação dos chromatophoros da pelle.

\section{A SYMBIOSE}

A symbiose não deve ser confundida com o parasitismo, jorque aquella é uma como que alliança, emquanto que este é o ganho vital de um ser com prejuizo da integridade do outro. 
E' a symbiose o caracteristico de defesa mais geral da natureza organisada.

Ella é a convivencia de seres na defesa commum de sua integridade.

Encaramol-a sob tres aspectos: commensalismo, mutualismo e epocuminismo.

Chama-se commensalismo a convivencia de dois ou mais seres na qual um delles vive á custa do outro, seja de restos buccaes, seja de dejeç̧ões.

A symbiose denomina-se mutualismo quando diversos seres vivem em reciprocidade de interesses.

Entende-se por epocuminismo a vantagem de que gosam certos animaes de serem transportados por outros.

A symbiose se dá de preferencia:

$\left.1^{\circ}\right)$ na fauna e flora maritimas;

$\left.2 .^{\circ}\right)$ entre os insectos;

3. $\left.{ }^{\circ}\right)$ entre vertebrados;

$\left.4 .^{\circ}\right)$ entre plantas e animaes.

Como exemplos de symbiose na fauna e flora maritimas temos o Bernardus pagurus, tambem chamado Bernardo o ermitão, arthropode que se aloja na concha da Hydractinia para se esconder de seus inimigos ou para, a socapa, atacar a sua presa; a Adamsia (anemona), a Suberita (esponja) e o Nureilepas (annelideo) defendendo-se contra os peixes que os perseguem, devido ao seu excellente abdomen, escondem-se sempre com um dos seus alliados numa concha ou caramujo; o Primothero, arthropode que no outomno vive com um marisco; a Rhizostoma cuviéri, medusa que abriga a Clupea pilchardus (sardinha); o Fiaresfer acus, peixe que se encontra no anus do Holothurio (echinoderma radiado) vivendo ás expensas das dejecções deste em symbio-epocumini-commensalismo. A esse respeito diz Emery que o Holothurio é um animal reintegrador porque quando perseguido pelo Fiaresfer expelle todo o apparelho digestivo, reintegrando-o depois, ao fim de alguns dias, o que não impediu de serem encontrados nelle aquelles peixes em numero de cinco, seis e mesmo sete. Ha aqui ainda um frisante exemplo de symbio-epocumini-commensalismo que é o da Remora (peixe) que se fisga ao dorso do tubarão, transportando-se e comendo-lhe as sobras alimentares. 
O exemplo mais notavel de symbiose na flora maritima é o da alga com o cogumelo, a primeira dando substancias carbonadas emquanto que o segundo lhe fornece em troca substancias azotadas; dessa permuta surge o lichen e é tal o mutualismo entre elles que a separação será fatal para ambos. Facto interessante tambem é a symbiose das Polinilaceas (algas) com a Paranusia bursaria (infusorio), ao ponto de se suppor que este animal tivesse chlorophylla.

Como exemplo de symbiose entre insectos citemos em primeiro lugar os trabalhos dos grandes entomologistas Wassmann e Echerich que, na sua "Symphilia" apontam 1.246 hospedes commensaes nos formigueiros e cupins.

Esses hospedes na sua maioria eram commensaes e mutualistas ao mesmo tempo e soffreram modificações:

1) na reducção do seu apparelho buccal acostumado á nova qualidade de alimento;

2) na transformação parcial das antennas, persistindo a apprehensão ;

3) na presença de orgams de exsudação.

Os commensaes, uma vez hospedados, tomam habitos mimecophilos, isto é, tornam-se amigos das formigas. Essa amisade por outro lado é reciproca, porque as thermitas apreciam extraordinariamente um liquido secretado pelas glandulas abdominaes (trichomas) desses insectos.

Outros exemplos de symbio-commensalismo entre os inse' ‘tos são: a Oxhymosa oberthiri que em busca da exsudação da formiga ataca-a dominando-a para lhe sugar o abdomen rico $€ m$ liquido formico; a Claviger testaceus que é hospedada pela ihermita Lasius flavius; o Formicoxenus nitidulus cohabitante da Formica rufa e da Formica pratensis antennal (vulgarmente içá ou saúva), a Pratyarthus hoffmannseggi que tem a particularidade de se hospedar em qualquer formigueiro; a Penzig silvestri (cigarra) que hospeda uma ou mais formigas que se aproveitam de sua exsudação; e finalmente, a Euthermes trigona (thermita) commensal do Orthogonius termiticole (vespa).

A symbiose entre vertebrados apresenta casos curiosos como os que notou Schilling e aos quaes denominou "trifoglio", taes como os dos mammiferos girafa e elephante em que aquella concorre com a vista e este com o olfacto; entre gazellas e an. 
tílopes; entre o rhinoceronte e a bufaga (ave); entre o boi e o gavião (rapåce).

Entre os casos de symbiose de plantas e animaes temos os da zoocrorella (alga) e a Amoeba (rhizopode) vivendo em symbio-mutualismo; o Heterodera radicicola que, habitando as raizes de outras plantas do deserto, produz tuberculos aquosos uteis á planta durante a estação da secca; e, no Japão, ha exemplos de arvores fructiferas que alimentam as thermitas com o seu nectar dimanado dos troncos, dos galhos e das folhas, para evitar que aquellas lhes invadam o periantho, isto é, o seu thalamo.

Temos a Cecropia adenopus (embaúva) que hospeda a Azteca instabilis (thermita) e a Nepenthes bicalcarata que dá hospedagem á Cordia nodosa (thermita).

Curiosissimo é o facto de symbio-commensalismo denominado por Ule Kwaner - jardim suspenso - o qual contem uma thermita cephalote que devora o prosenchyma dos caules e das folhas.

Do que aqui fica ligeiramente exposto conclue-se - em que pese ao modo de pensar dos finalistas - que as especies foram creadas, não para um genero de vida determinado, mas para o genero de vida que lhes impõem as circumstancias nas quaes se acham collocadas.

Para enfrentar a desoladora verdade da selecção natural de que "só os mais fortes triumpham", possuem ellas tres formidaveis armas: a resistencia (resistir), o mimetismo (fingir), a symbiose (alliar) 